\title{
QTL mapping of Fusarium head blight resistance in three related durum wheat populations
}

\author{
Noemie Prat ${ }^{1,2,3} \cdot$ Camille Guilbert $^{1} \cdot$ Ursa Prah $^{1} \cdot$ Elisabeth Wachter $^{1}$. \\ Barbara Steiner $^{1} \cdot$ Thierry Langin $^{2} \cdot$ Olivier Robert $^{3} \cdot$ Hermann Buerstmayr $^{1}$
}

Received: 28 June 2016 / Accepted: 3 September 2016 / Published online: 23 September 2016

(C) The Author(s) 2016. This article is published with open access at Springerlink.com

\begin{abstract}
Key message The QTL Fhb1 was successfully introgressed and validated in three durum wheat populations. The novel germplasm and the QTL detected will support improvement of Fusarium resistance in durum wheat.

Abstract Durum wheat (Triticum durum Desf.) is particularly susceptible to Fusarium head blight (FHB) and breeding for resistance is hampered by limited genetic variation within this species. To date, resistant sources are mainly available in a few wild relative tetraploid wheat accessions. In this study, the effect of the well-known hexaploid wheat (Triticum aestivum L.) quantitative trait locus (QTL) Fhbl was assessed for the first time in durum wheat. Three F7-RIL mapping populations of about 100 lines were developed from crosses between the durum wheat experimental line DBC-480, which carries an Fhbl introgression from Sumai-3, and the European T. durum cultivars Karur, Durobonus and SZD1029K. The RILs were evaluated in field experiments for FHB resistance in three seasons
\end{abstract}

Communicated by T. Miedaner.

Electronic supplementary material The online version of this article (doi:10.1007/s00122-016-2785-0) contains supplementary material, which is available to authorized users.

Hermann Buerstmayr

hermann.buerstmayr@boku.ac.at

1 Department of Agrobiotechnology, Institute of Biotechnology in Plant Production, BOKU-University of Natural Resources and Life Sciences Vienna, Konrad Lorenz Str. 20, 3430 Tulln, Austria

2 INRA, UBP, Genetics, Diversity and Ecophysiology of Cereals, GDEC, 63039 Clermont-Ferrand Cedex 2, France

3 Florimond-Desprez, 3 rue Florimond-Desprez, BP 41, 59242 Cappelle-en-Pevele, France using spray inoculation and genotyped with SSR as well as genotyping-by-sequencing markers. QTL associated with FHB resistance were identified on chromosome arms 2BL, 3BS, 4AL, 4BS, 5AL and 6AS at which the resistant parent DBC-480 contributed the positive alleles. The QTL on 3BS was detected in all three populations centered at the $F h b l$ interval. The Rht-Bl locus governing plant height was found to have a strong effect in modulating FHB severity in all populations. The negative effect of the semi-dwarf allele $R h t-B 1 b$ on FHB resistance was compensated by combining with $F h b 1$ and additional resistance QTL. The successful deployment of Fhbl in T. durum was further substantiated by assessing type 2 resistance in one population. The efficient introgression of $F h b 1$ represents a significant step forward for enhancing FHB resistance in durum wheat.

\section{Introduction}

Fusarium head blight (FHB), caused mainly by Fusarium graminearum and Fusarium culmorum, is one of the major fungal diseases affecting wheat production almost worldwide (Parry et al. 1995). The direct consequences of FHB are yield losses and seed quality reductions in both common wheat (Triticum aestivum) and durum wheat (Triticum durum) (McMullen et al. 2012). The contamination of infected grains with Fusarium mycotoxins is highly problematic, rendering harvests unfit for food and feed (Pestka 2010; Covarelli et al. 2014). Mycotoxin contamination is of particular concern in durum wheat as it is mainly utilized for human consumption. Host plant resistance is considered pivotal for an integrated plant protection strategy to control and reduce FHB damages (Gilbert and Haber 2013).

FHB is a complex disease and its response shows polygenic inheritance modulated by environmental factors with 
significant genotype-by-environment interactions (Buerstmayr et al. 2009; Löffler et al. 2009). Several components of resistance have been defined (Schroeder and Christensen 1963; Mesterházy 1995), among which resistance to initial infection (type 1) and resistance to fungal spread within infected spikes (type 2) are commonly accepted and have been widely investigated in QTL mapping studies. Under field conditions, the overall FHB resistance is usually assessed through scoring of disease severity after spray inoculation and is considered to reflect the genotypic response during natural epidemics. Both active and passive mechanisms influence FHB resistance (Mesterházy 1995). The latter include morphological and developmental features which affect primary fungal infection and/or disease development through disease escape mechanisms. Plant height is one of the foremost morphological traits affecting FHB response and the widely deployed Norin 10 semidwarfing Rht alleles, namely Rht-Blb and Rht-Dlb, have been found associated with increased FHB severity under field conditions in common wheat (Hilton et al. 1999; Miedaner and Voss 2008; Voss et al. 2008) and in durum wheat (Buerstmayr et al. 2012). Their effect on FHB development may be imputed to plant height per se and differences in canopy structure (Yan et al. 2011) as well as to pleiotropic physiological effects of the Rht genes and/or the presence of tightly linked genes (Srinivasachary et al. 2009; Saville et al. 2012).

Compared to common wheat, limited efforts have been dedicated to improve FHB resistance in durum wheat (Buerstmayr et al. 2009). Most current durum wheat cultivars are highly susceptible and breeding progress is hampered by the narrow genetic variation for FHB resistance in durum wheat elite germplasm. Extensive screening of large germplasm collections identified only few durum landraces with improved levels of resistance (Elias et al. 2005; Talas et al. 2011; Huhn et al. 2012). Alternative sources of resistance have been screened in the related tetraploid species of Triticum turgidum to identify resistance donors for breeding (Buerstmayr et al. 2003b; Oliver et al. 2007, 2008). A relatively small number of QTL mapping studies aimed at dissecting the genetic architecture of FHB resistance in tetraploid wheat to date and have been recently reviewed by Prat et al. (2014). QTL descending from Triticum dicoccoides accessions Israel A, PI478742, Mt. Hermon\#22, and Mt. Gerizim\#36 have been identified on chromosomes 3A (Otto et al. 2002; Gladysz et al. 2007; Chen et al. 2007; Buerstmayr et al. 2013; Zhu et al. 2016b), 4A (Gladysz et al. 2007), 6B (Buerstmayr et al. 2013) and 7A (Kumar et al. 2007). Triticum dicoccum accessions PI 41025, Td-161 and BGRC3487 provided resistance QTL on 3A, 3B, 4B, 5A, 6A, 6B, 7A and 7B (Buerstmayr et al. 2012; Ruan et al. 2012; Zhang et al. 2014). Triticum carthlicum accession Blackbird contributed one resistance QTL mapping to 6B (Somers et al. 2006). The dissection of the genetic architecture of resistant $T$. durum Tunisian landraces by association mapping located a QTL on 3B (Ghavami et al. 2011). In mapping studies based on crosses between susceptible durum cultivars and other resistant sources, a few resistance-conferring QTL alleles were contributed by the susceptible durum parents, notably those on chromosomes $2 \mathrm{~A}, 2 \mathrm{~B}, 3 \mathrm{~B}$ and $5 \mathrm{~B}$ from cultivars Ben (Zhang et al. 2014), Strongfield (Somers et al. 2006), Floradur (Buerstmayr et al. 2012) and Lebsock (Ghavami et al. 2011), respectively.

The QTL detected in tetraploid wheat have failed so far to provide similarly high levels of resistance such as Fhbl, the major resistance QTL identified in common wheat cultivar Sumai-3 (Waldron et al. 1999; Anderson et al. 2001). Near diagnostic markers for Fhbl are available (Liu et al. 2008; Schweiger et al. 2016) and have been successfully implemented into applied wheat breeding using markerassisted selection (Anderson et al. 2007; Wilde et al. 2007; Salameh et al. 2011). Notwithstanding, the consequence of transferring this major QTL into tetraploid wheat has not been communicated until now. Here, we report on the effect of $F h b 1$ in three biparental populations that have been generated by crossing line DBC-480, an FHB-resistant experimental durum line possessing the Fhbl allele from Sumai3, with a modern European durum breeding line and two current durum cultivars. We also show the association of plant height with FHB resistance, and more specifically the effect of $R h t-B l$ and its interaction with $F h b l$ on disease severity in durum wheat.

\section{Materials and methods}

\section{Plant materials}

Three mapping populations comprising 111, 100 and $100 \mathrm{~F}_{7}$ RILs were developed by single seed descent from crosses of the tetraploid resistant line DBC-480 to the susceptible European T. durum cultivars Karur (KD) and Durobonus (DD) and the advanced breeding line SZD1029K (SD), respectively. Karur and Durobonus are registered varieties bred by RAGT, France (registered 2002), and Saatzucht-Donau, Austria (registered 2004), respectively. The breeding line SZD1029K was provided by Saatzucht-Donau for this study. The experimental line DBC-480 was developed at IFA-Tulln, Austria, by four generations of marker-assisted backcrossing of the highly resistant T. aestivum cultivar Sumai-3 into the background of the Austrian T. durum variety Semperdur and subjected to rigorous phenotypic selection for improved FHB resistance in field trials (details not shown). The presence of the resistant allele at $F h b l$ was verified using the SSR markers 
Xgwm389, Xgwm533 and Xgwm493. Karur, Durobonus and SZD1029K possess the semi-dwarfing allele Rht-B1b, while DBC-480 is a tall line that harbors the Rht-Bla wildtype allele.

\section{FHB resistance phenotyping}

The three mapping populations along with their parental lines were evaluated in multiple field experiments at IFATulln, Austria $\left(16^{\circ} 04,16^{\prime} \mathrm{E}, 48^{\circ} 19,08^{\prime} \mathrm{N}, 177 \mathrm{~m}\right.$ above sea level) in 2013, 2014 and 2015. Experiments were laid out as randomized complete block designs with two blocks in 2013 and three blocks in 2014 and 2015. Plots consisted of single rows in 2013 and double rows of $1 \mathrm{~m}$ length at $17 \mathrm{~cm}$ spacing in 2014 and 2015. Sowing of the individual blocks was performed in early spring and staggered 1-2 weeks apart leading to slightly different flowering dates between the blocks. Management of the field trials was conducted following good agronomical practice as described in Buerstmayr et al. (2002). At anthesis, trials were spray inoculated using a motor-driven backpack sprayer in the late afternoons with the virulent DON-producing F. culmorum isolate $\mathrm{Fc} 91015$ at a conidial concentration of $2.5 \times 10^{4} \mathrm{ml}^{-1}$. Inoculum suspension was prepared by utilizing the protocol described in Buerstmayr et al. (2000). Aliquots of conidia stock solutions were stored at $-30{ }^{\circ} \mathrm{C}$ then thawed at $37{ }^{\circ} \mathrm{C}$ and diluted with deionized water to achieve the desired final spore concentration just prior to inoculation. Inoculations were performed within each block on all plots, starting when $50 \%$ of the plants in the earliest plot of a block reached anthesis. Inoculations were repeated at 2-day intervals and ended 2 days after the last plot of the block flowered, resulting in up to six inoculum applications per block. At each inoculation cycle, about $100 \mathrm{ml} \mathrm{m}^{-2}$ of conidial suspension was sprayed onto the durum wheat heads. The crop canopy was kept moist by mist irrigating during $20 \mathrm{~h}$ after inoculations to facilitate spore germination and infection. FHB severity was visually estimated as the percentage of infected spikelets within each plot on days 14, 18, 22 and 26 after anthesis. In 2013, scoring was performed at two time points: 18 and 26 days after anthesis. The area under the disease progress curve (AUDPC) was calculated and used as an integrated measure of overall disease severity as described by Buerstmayr et al. (2000). At all experimental plots, plant height (PH) was measured in centimeter and flowering date was recorded and converted into number of days after May 1.

The KD population and the respective parental lines Karur and DBC-480 were also tested in the greenhouse for FHB spread within the spike (type 2 resistance) using single-floret inoculation in three unreplicated greenhouse trials at Florimond-Desprez (France) in winter 2015 (GH1) and at IFA-Tulln in summer 2016 (GH2 and GH3). Seeds were germinated in multi-trays and subjected to a cold treatment at $5{ }^{\circ} \mathrm{C}$ for 1 week. Ten seedlings per line were planted in 7.5-1 pots ( $23.5 \mathrm{~cm}$ diameter, $23 \mathrm{~cm}$ height $)$ filled with a standard potting mix consisting of $70 \%$ recycled compost, $28 \%$ peat and $2 \%$ silica sand. Pots were designated as experimental units and arranged in a randomized design. The temperature in the greenhouse was maintained at $22 / 18{ }^{\circ} \mathrm{C}$ (day/night) with a 16 -h photoperiod. Management of the greenhouse trial was essentially as described by Buerstmayr et al. (2013). Inoculations were performed at anthesis by pipetting $10 \mu \mathrm{l}$ of conidia suspension between the lemma and palea of the four outer florets of two central spikelets per spike using the same inoculum preparation and concentration as for the field experiments. High humidity was ensured to promote fungal infection by covering the spikes with translucent polyethylene bags for $24 \mathrm{~h}$. Type 2 resistance was assessed as the percentage of infected spikelets per spike (PIS) measured at 24 days post-inoculation by counting the number of infected spikelets and the total number of spikelets per spike. On average, eight spikes per genotype were inoculated in each experiment. Plant height was recorded at each greenhouse pot.

\section{Phenotypic data analysis}

Statistical analysis was performed in R 3.1.3 ( $\mathrm{R}$ Core Team 2015) using the lme4 package for mixed model analysis (Bates et al. 2015). For each trait under investigation, a linear mixed model was fitted for each population with all three experiments combined: (1) $P_{i j k}=\mu+G_{i}+E_{j}+E_{j}\left(R_{k}\right)+G_{i} \times E_{i}+e_{i j k}$, where $P_{i j k}$ is the phenotypic value, $\mu$ the population mean, $G_{i}$ the effect of the ith genotype, $E_{j}$ the effect of the jth experiment, $E_{j}\left(R_{k}\right)$ the effect of the kth replicate within the jth experiment, $G_{i} \times E_{i}$ the ijth effect of the genotype-byexperiment interaction and $e_{i j k}$ designated the residual. The genotype effect was treated as fixed and all other terms as random effects. For single experiments, a reduced linear mixed model was fitted: (2) $P_{i k}=\mu+G_{i}+R_{k}+e_{i k}$, where $P_{i k}$ is the phenotypic value, $\mu$ the population mean, $G_{i}$ the effect of the ith genotype, $R_{k}$ the effect of the kth replicate (block) and $e_{i k}$ the residual. The genotype effect was again treated as fixed and the replication as random effect.

Fixed and random effects of the models were tested one by one using the likelihood ratio test (LRT). Best linear unbiased estimates (BLUES) of each genotype were computed for the different phenotyped traits according to model (1) for the analysis across experiments and according to model (2) for an analysis within individual experiments. BLUES calculated across experiments are also referred to as overall means. Broad-sense heritability $\left(\mathrm{H}^{2}\right)$ was estimated using variance components determined by the restricted maximum likelihood (REML) method 
setting all effects as random and based on the equation $H^{2}=\sigma_{G}^{2} /\left(\sigma_{G}^{2}+\sigma_{G \times E}^{2} / m+\sigma_{e}^{2} / p\right)$, where $\sigma_{G}^{2}$ denotes the genotypic variance, $\sigma_{\mathrm{G} \times \mathrm{E}}^{2}$ the genotype-by-experiment interaction variance, $\sigma_{e}^{2}$ the error variance, $m$ the number of experiments and $\mathrm{p}$ the total number of replications across experiments (Holland et al. 2003).

\section{Marker data and genetic map construction}

Genomic DNA was extracted from fresh leaves of ten pooled plants of each line using a simplified CTAB-based procedure modified from Saghai-Maroof et al. (1984). High-density genotyping of all individuals was performed using genotyping-by-sequencing (GBS) with the DArTseq platform (DArT PL, Canberra, Australia). Markers identified by the DArTseq assay include SNPs as well as the presence-absence variations (PAV) ( $\mathrm{Li}$ et al. 2015). Markers were filtered based on a reproducibility $\geq 95 \%$. Furthermore, PAV with $\geq 10 \%$ missing data and SNP markers with $\geq 10 \%$ missing data or heterozygotes were removed for each population separately. Markers showing significant $(p<0.01)$ segregation distortion were also discarded. Finally, a total of 7965, 4150 and 6235 high-quality polymorphic DArTseq markers were available for mapping in the KD, DD and SD populations, respectively. All lines were genotyped with the two selected markers Xbarc147 (Song et al. 2005) and Xumn10 (Liu et al. 2008) that are known to be linked with $F h b 1$ as well as with allele-specific markers for Rht-BI (Ellis et al. 2002).

\section{Linkage map construction}

Linkage maps for each population were constructed using the MSTmap algorithm (Wu et al. 2008) included in the R package ASMap v0.4 (Taylor and Butler 2015). The objective function was set to minimize the sum of recombination events between markers for map construction. In a first step, robust linkage groups where constructed using a $p$ value threshold set to $1 \times 10^{-8}$, and the assignment of the linkage groups to chromosome was performed by comparing the location of markers to the wheat DArTseq consensus map provided by DArT PL (A. Kilian, Diversity Arrays Technologies, personal communication, 2016). In a second step, genotypic data were pooled on a chromosome basis and regrouped at a less stringent threshold using a $p$ value of $1 \times 10^{-6}$. Distances were calculated with the Kosambi mapping function. Genetic maps were drawn on MapChart software (Voorrips 2002) and collinearity among the individual maps was checked.

\section{QTL mapping}

Quantitative trait loci analysis was performed for each trait with the BLUES calculated for each individual experiment and across experiments using the R package R/qtl (Broman et al. 2003). Missing genotypic information was imputed using the multiple imputation method of Sen and Churchill (2001). The main effect QTL were detected by performing interval mapping and composite interval mapping via Haley-Knott regression. For composite interval mapping, the number of marker covariates was selected by a forward approach, while setting a window size of $10 \mathrm{cM}$. LOD significance threshold for type I error rate $\alpha=0.05$ were obtained for each trait and experiment based on a 1000 permutations test. Significant QTL were subsequently fitted using a multiple QTL model. The existence of further QTL and the presence of QTL-by-QTL interaction were tested using the addqtl and addint functions, respectively. The final multiple QTL model was fitted against the null model by ANOVA and the percentage of phenotypic variance explained by each QTL, the additive effects as well as LOD scores were estimated. Confidence intervals were defined for each QTL by calculating a 1.5-LOD support interval.

\section{Results}

\section{Trait variations and correlations}

Evaluation of FHB severity was performed on three biparental populations in artificially inoculated field trials to investigate the relevant factors that play a role in reducing FHB disease under natural conditions. In all experiments, the common resistant parent DBC-480 was significantly less diseased than the susceptible parents. The average AUDPC value across experiments of the resistant parental line DBC-480 was 125 (corresponding to an average of $12 \%$ symptomatic spikelets 26 days after flowering), while Karur, Durobonus and SZD1029K had approximately fivefold higher AUDPC values (Table 1). Large variation was observed within each population (Fig. 1), but also between populations where the average FHB severity was lowest in the KD population and highest in the SD population. Transgressive segregation was observed in all populations and some lines showed lower disease symptoms than the resistant parent DBC-480, although these differences were not statistically significant. Disease pressure between experiments was comparable in 2013 and 2014, while the experiment of 2015 showed overall higher symptoms. AUDPC broad-sense heritability for means across experiments was high and within the same range for the three populations $\left(0.74<H^{2}<0.89\right)$, as in all cases, genotypic variances were higher than variances due to genotype $\times$ experiment interaction and residual error (Online Resource 1). Significant genotypic effects for all traits were revealed by ANOVA.

To evaluate specific type 2 component of resistance as conferred by $F h b 1$, the percentage of infected spikelets per 
Table 1 Means of parents and mean, minimum and maximum values of populations, least significant differences at $\alpha<0.05\left(\mathrm{LSD}_{0.05}\right)$ and broad-sense heritability coefficient $\left(H^{2}\right)$ or repeatability of analyzed traits in field and greenhouse $(\mathrm{GH})$ experiments

\begin{tabular}{|c|c|c|c|c|c|c|c|c|c|c|}
\hline & \multicolumn{5}{|l|}{ Parents } & \multicolumn{5}{|c|}{ Population } \\
\hline & \multirow[t]{2}{*}{ DBC-480 } & \multirow[t]{2}{*}{ Karur } & \multirow{2}{*}{\multicolumn{2}{|c|}{ Durobonus }} & \multirow[t]{2}{*}{ SZD1029K } & \multicolumn{5}{|l|}{$\mathrm{KD}$} \\
\hline & & & & & & Mean & Min & $\operatorname{Max}$ & $\mathrm{LSD}_{0.05}$ & $H^{2}$ \\
\hline \multicolumn{11}{|l|}{ FHB severity (AUDPC) } \\
\hline Overall mean & 125 & 642 & \multicolumn{2}{|c|}{693} & 845 & 360 & 65 & 816 & 117 & 0.89 \\
\hline 2013 & 126 & 668 & \multicolumn{2}{|c|}{601} & 874 & 272 & 23 & 830 & 258 & $0.66^{\mathrm{c}}$ \\
\hline 2014 & 54 & 457 & \multicolumn{2}{|c|}{567} & 519 & 289 & 16 & 781 & 175 & $0.87^{\mathrm{c}}$ \\
\hline 2015 & 200 & 805 & \multicolumn{2}{|c|}{917} & 1130 & 516 & 94 & 1128 & 185 & $0.92^{\mathrm{c}}$ \\
\hline FHB spread (PIS $\left.{ }^{b}\right)$ & 18.3 & 38.4 & \multicolumn{2}{|c|}{ - } & - & 30.2 & 11.6 & 62.6 & 25.4 & 0.51 \\
\hline Flowering date $^{\mathrm{a}}$ & 40.3 & 40.1 & \multicolumn{2}{|c|}{40.1} & 40.1 & 39.6 & 37.6 & 41.9 & 1.1 & 0.67 \\
\hline Plant height $(\mathrm{cm})$ in field & 110 & 73 & \multicolumn{2}{|c|}{67} & 61 & 97 & 67 & 126 & 5 & 0.98 \\
\hline \multirow[t]{4}{*}{ Plant height $(\mathrm{cm})$ in $\mathrm{GH}$} & 119 & 71 & - & & - & 105 & 65 & 143 & 12 & 0.97 \\
\hline & \multicolumn{10}{|l|}{ Population } \\
\hline & \multicolumn{5}{|l|}{ DD } & \multicolumn{5}{|l|}{ SD } \\
\hline & Mean & Min & $\operatorname{Max}$ & $\mathrm{LSD}_{0.05}$ & $H^{2}$ & Mean & Min & $\operatorname{Max}$ & $\mathrm{LSD}_{0.05}$ & $H^{2}$ \\
\hline \multicolumn{11}{|l|}{ FHB severity (AUDPC) } \\
\hline Overall mean & 451 & 110 & 1152 & 142 & 0.78 & 667 & 131 & 1237 & 136 & 0.74 \\
\hline 2013 & 292 & 47 & 699 & 210 & $0.61^{c}$ & 401 & 47 & 915 & 249 & $0.69^{c}$ \\
\hline 2014 & 240 & 32 & 768 & 151 & $0.84^{\mathrm{c}}$ & 328 & 28 & 903 & 165 & $0.86^{\mathrm{c}}$ \\
\hline 2015 & 791 & 201 & 1718 & 302 & $0.93^{c}$ & 1257 & 251 & 2031 & 264 & $0.96^{\mathrm{c}}$ \\
\hline FHB spread (PIS $\left.{ }^{b}\right)$ & - & - & - & - & - & - & - & - & - & - \\
\hline Flowering date ${ }^{\mathrm{a}}$ & 39.3 & 36.5 & 41.7 & 1.2 & 0.76 & 41 & 38.3 & 43.3 & 1.1 & 0.81 \\
\hline Plant height $(\mathrm{cm})$ in field & 95 & 68 & 121 & 6 & 0.97 & 85 & 54 & 123 & 5 & 0.99 \\
\hline Plant height $(\mathrm{cm})$ in $\mathrm{GH}$ & - & - & - & - & - & & - & - & - & - \\
\hline
\end{tabular}

${ }^{\text {a }}$ Number of days from May 1 to anthesis

b Percentage of infected spikelets

${ }^{c}$ Repeatability

spike (PIS) was measured in three glasshouse experiments for the KD population. Heritability for PIS was moderate, $H^{2}=0.51$, although ANOVA showed significant genotype effects for the 111 RILs (Table 1, Online Resource 1). Some of the RILs showed transgressive segregation for type 2 resistance, although only significant for higher susceptibility. As expected, DBC-480 showed less disease symptoms than Karur with an average of 18.3 and $38.4 \%$ PIS, respectively (Fig. 1). Weak but significant correlation was observed between the means of FHB spread and FHB severity $(r=0.2, p<0.05)$.

Variation for plant height was apparent in the three populations (Fig. 1). The susceptible parents Karur, Durobonus and SZD1029K were 38-49 $\mathrm{cm}$ shorter than the resistant donor DBC-480. PH showed a bimodal frequency distribution in the KD and DD populations, while a trimodal distribution was displayed in the SD population (Fig. 1). FHB severity was negatively correlated with $\mathrm{PH}$ within all populations (Table 2), accordingly shorter plants showed higher FHB severity. On the contrary, FHB spread after point inoculation (PIS) showed no significant correlation with PH. Distribution of date of anthesis showed continuous variation in all populations, although no significant difference in flowering date was observable among the parents. FHB severity and flowering date were significantly positively correlated in the SD population across experiments, while a weak negative correlation and no evidence for significant correlation were observed in the KD and DD populations, respectively (Table 2). Within individual experiments, however, correlation analysis showed no significant association between disease severity and date of anthesis in 2013 and 2015 for the KD population in 2013 and 2014 for the DD population and in 2014 for the SD population (Online Resource 2). 

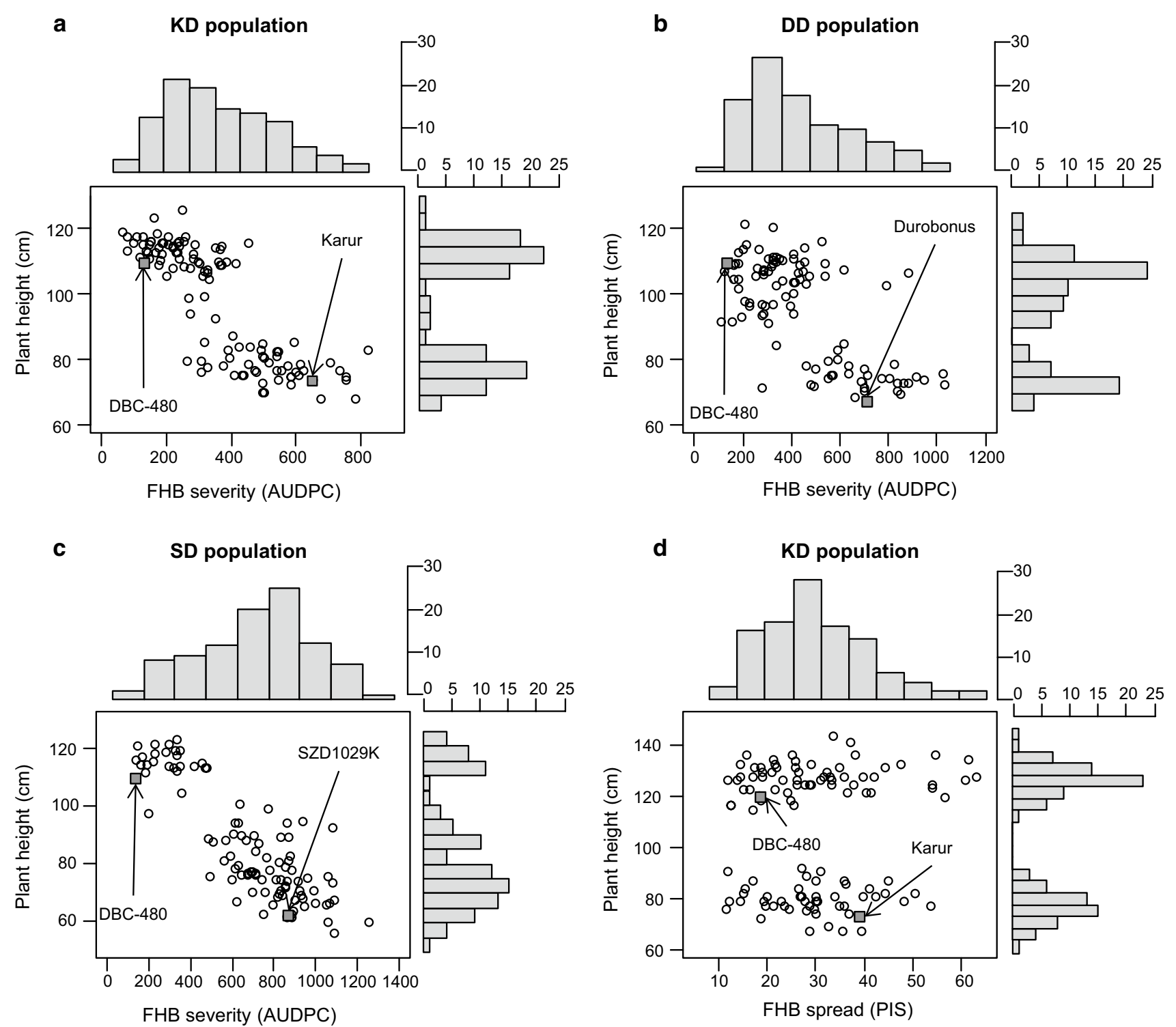

Fig. 1 Scatter plots and marginal histograms of frequency distribution of overall means for FHB severity (AUDPC) against plant height $(\mathrm{cm})$ measured in the field trials for each population $(\mathbf{a}-\mathbf{c})$

and for FHB spread (PIS) again plant height $(\mathrm{cm})$ measured in the greenhouse trials for the KD population $(\mathbf{d})$. Parents are indicated by arrows

Table 2 Pearson correlation coefficients between FHB severity (AUDPC), plant height $(\mathrm{cm})$ and flowering date (days after May 1) for the overall means

\begin{tabular}{lllr}
\hline & \multicolumn{4}{l}{ FHB severity (AUDPC) } \\
\cline { 2 - 4 } & KD & DD & \multicolumn{1}{c}{ SD } \\
\hline Plant height & $-0.82^{* * *}$ & $-0.67 * * *$ & $-0.85^{* * *}$ \\
Flowering date & $-0.20^{*}$ & 0.15 n.s. & $0.43^{* * *}$ \\
\hline
\end{tabular}

n.s. non-significant

$* p<0.05$

$* * * p<0.001$

\section{QTL analysis}

\section{Generation of linkage maps}

7975,4153 and 6242 polymorphic markers were generated from DARTseq and SSR marker data for the KD, DD and SD populations, respectively. Of these markers, 1064 were common across all three populations. The number of markers within maps for the $\mathrm{KD}$, DD and SD populations was reduced to 1609,1052 and 1006 unique loci, respectively. The total map lengths were 2806, 1781 and $2219 \mathrm{cM}$ with 
Table 3 Locations and estimates of QTL for FHB severity (AUDPC) using multiple QTL mapping

\begin{tabular}{|c|c|c|c|c|c|c|c|c|c|c|c|}
\hline \multirow[t]{2}{*}{ Population } & \multirow[t]{2}{*}{ Chr. } & \multirow[t]{2}{*}{ Closest marker } & \multicolumn{3}{|c|}{ Overall mean } & \multicolumn{2}{|l|}{2013} & \multicolumn{2}{|l|}{2014} & \multicolumn{2}{|l|}{2015} \\
\hline & & & $\mathrm{Add}^{\mathrm{a}}$ & $\% \mathrm{PV}^{\mathrm{b}}$ & $\mathrm{LOD}^{\mathrm{c}}$ & $\% \mathrm{PV}^{\mathrm{b}}$ & $\operatorname{LOD}^{c}$ & $\% \mathrm{PV}^{\mathrm{b}}$ & $\overline{L O D}$ & $\% \mathrm{PV}^{\mathrm{b}}$ & $\mathrm{LOD}^{\mathrm{c}}$ \\
\hline $\mathrm{KD}$ & $2 \mathrm{BL}$ & 1072874 & 37 & 4.3 & 4.8 & - & - & 7.2 & 5.5 & - & - \\
\hline DD & $3 B S$ & 4410793 & 86 & 14.0 & 8.7 & - & - & 16.0 & 4.7 & 12.2 & 7.6 \\
\hline $\mathrm{KD}$ & $3 B S$ & Xbarc147 & 60 & 11.1 & 10.8 & 14.1 & 5.5 & 12.8 & 9.0 & 6.1 & 5.6 \\
\hline SD & $3 B S$ & Xbarc147 & 60 & 5.0 & 3.3 & - & - & 8.1 & 3.8 & - & - \\
\hline SD & 4AL & 4541598 & 123 & 18.8 & 10.4 & - & - & 15.4 & 6.7 & 14.4 & 6.6 \\
\hline DD & 4BS & RhtB1 & 156 & 38.4 & 18.6 & 18.8 & 6.0 & 26.0 & 7.1 & 55.5 & 23.1 \\
\hline $\mathrm{KD}$ & $4 \mathrm{BS}$ & RhtB1 & 140 & 64.2 & 35.0 & 29.1 & 10.2 & 47.6 & 23.7 & 69.0 & 33.2 \\
\hline SD & 4BS & RhtB1 & 126 & 19.4 & 10.7 & - & - & 10.3 & 4.7 & 16.0 & 7.2 \\
\hline DD & $5 \mathrm{AL}$ & 1111359 & 59 & 6.2 & 4.3 & 15.0 & 5.0 & - & - & - & - \\
\hline SD & 6AS & 4008755 & 139 & 24.9 & 12.9 & 28.0 & 6.9 & 24.6 & 9.8 & 25.4 & 10.6 \\
\hline
\end{tabular}

a Positive additive effects denote trait-increasing effect of the DBC-480 allele; additive effects were estimated as half the difference between phenotype averages for the homozygote

b Percentage of phenotypic variance explained by the QTL

c LOD (logarithm of the odds) above the threshold at the 0.05 level of probability obtained through a 1000 -iteration permutation test an average marker distance of $1.9,1.7$ and $2.5 \mathrm{cM}$ for the $\mathrm{KD}$, DD and SD populations, respectively. Each linkage group could be unambiguously assigned to a chromosome based on the wheat DArTseq consensus map. Alignment to the consensus map showed low-coverage regions for the DD and SD populations on chromosomes $1 \mathrm{~A}$ and $3 \mathrm{~A}$ and on chromosomes 5A and 7A for the DD population. Despite that, all chromosomes were represented (Online Resource 3).

\section{QTL analysis for FHB severity}

QTL analysis conducted in individual populations identified a total of six genomic regions associated with FHB severity on chromosome arms $2 \mathrm{BL}$, 3BS, 4AL, 4BS, 5AL and 6AS (Table 3). The resistant parent DBC-480 contributed to the resistance, improving alleles at all loci. Linkage groups and confidence intervals of QTL are shown in Fig. 2. For reading ease, only selected markers at about $5 \mathrm{cM}$ distances are displayed, while more detailed information including all mapped markers with their positions can be found in Online Resource 4. The two genomic regions on 3BS and 4BS were found to be repeatedly associated with FHB resistance at the same location in all three populations. The major QTL on 4BS co-localized with the Rht-Bl locus, which explained 64, 38 and $19 \%$ of the total phenotypic variance in the KD, DD and SD populations, respectively. On chromosome 3BS, the QTL mapped to marker positions Xbarc147 and Xumn10, which signposts the position of the introgressed Fhbl and was detected for the analysis across experiments in all populations. The 3BS QTL was found consistently in all experiments for the KD population, while it was significant in two out of three experiments for the DD population and in one experiment for the SD population. The effects of the contrasting alleles at the $F h b 1$ and $R h t-B 1$ loci, as well as the effect of allelic combinations at these loci for the overall mean FHB severity are illustrated for each population in Online Resource 5. Analysis revealed further QTL specific to individual populations. Two major QTL were detected in the SD population on $4 \mathrm{AL}$ and 6AS explaining 19 and $25 \%$ of the total phenotypic variation. Both QTL overlapped with QTL associated with plant height and flowering date. In the DD population, a QTL on 5AL was found in the analysis across experiments where it contributed to $6 \%$ of the phenotypic variation and had a stronger effect in 2013 explaining $15 \%$ of the phenotypic variation while it was not significant in 2014 and 2015. A small effect QTL was detected on $2 \mathrm{BL}$ in the KD population which contributed to $4 \%$ of the phenotypic variance and was significant in 2014 and for the across-experiments analysis. There was no evidence for epistatic QTL interactions in any of the analyses; QTL for FHB severity acted thus in an additive manner.

\section{QTL analysis for FHB spread}

QTL detection for FHB spread in the KD population identified a QTL on 3BS which peaked at the SSR marker Xbarc147 and was thus located in the same region as FHB severity 3BS QTL, matching likewise with the $F h b 1$ locus. The resistance-conferring allele was derived from DBC-480. The QTL was consistently detected in all three individual experiments and for the analysis across all experiments in which it explained $33 \%$ of the phenotypic variation (Table 4). Two additional QTL were detected on $2 \mathrm{~A}$ and $4 \mathrm{AL}$ at which the allele of the durum cultivar Karur 


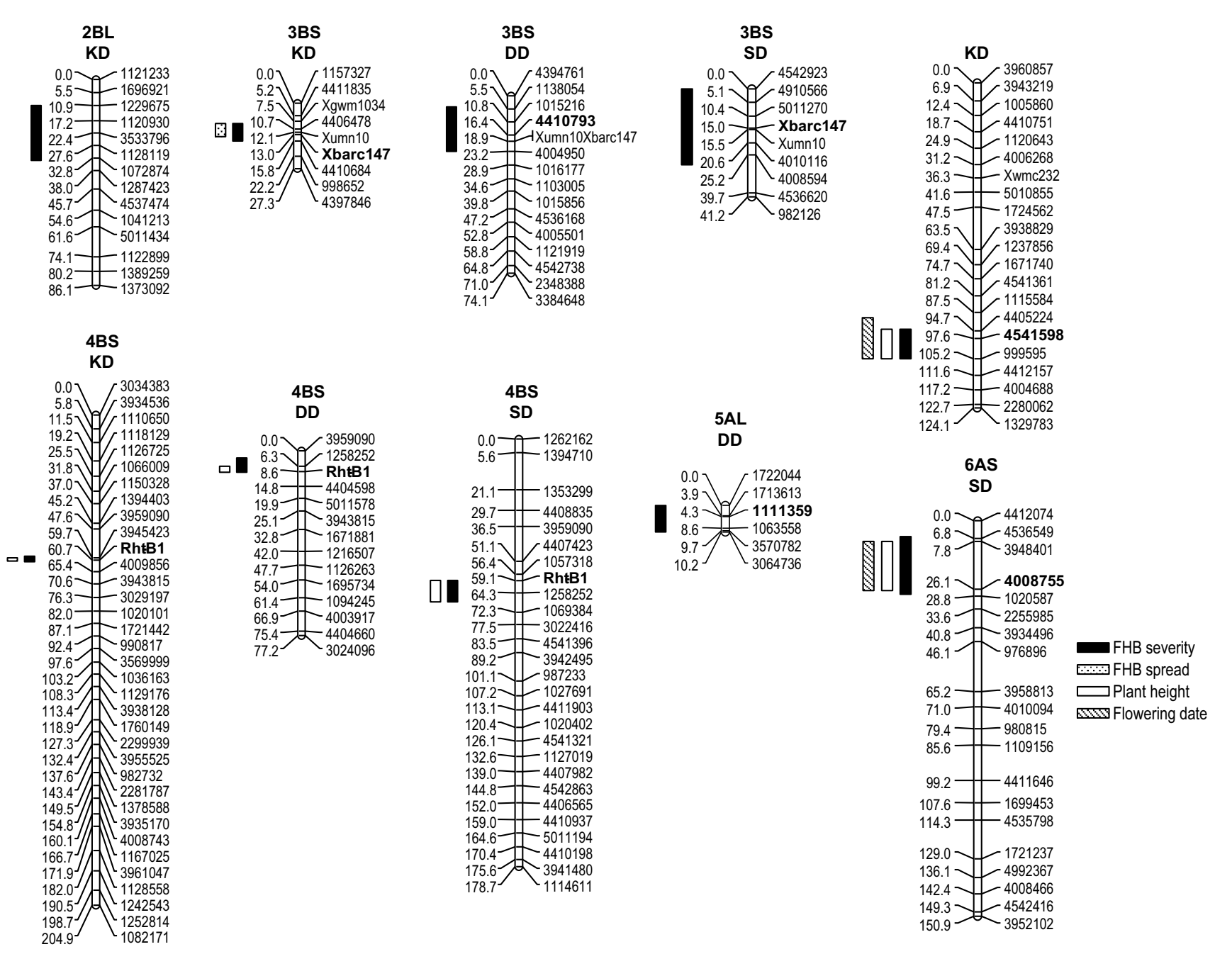

Fig. 2 Linkage maps and positions of QTL for FHB severity (AUDPC), FHB spread (percent of infected spikelets PIS) and coinciding morphological/developmental traits of the three populations

Table 4 Locations and estimates of QTL for FHB spread (percent of infected spikelets PIS) using multiple QTL mapping

\begin{tabular}{lllrrr}
\hline Experiment & Chr. & Closest marker & Add $^{\mathrm{a}}$ & $\% \mathrm{PV}^{\mathrm{b}}$ & LOD $^{\mathrm{c}}$ \\
\hline $\mathrm{GH} 1$ & 2A & 1698827 & -4.9 & 13.5 & 4.7 \\
$\mathrm{GH} 1$ & 3BS & Xbarc147 & 14.6 & 33.6 & 10.2 \\
$\mathrm{GH} 2$ & 3BS & 1032004 & 4.9 & 14.6 & 3.8 \\
GH3 & 3BS & Xbarc147 & 4.7 & 10.3 & 3.0 \\
Overall mean & 3BS & Xbarc147 & 7.4 & 33.3 & 9.7 \\
GH3 & 4AL & 1235993 & -5.2 & 12.6 & 3.6 \\
\hline
\end{tabular}

a Positive additive effects denote trait-increasing effect of the DBC480 allele; additive effects were estimated as half the difference between phenotype averages for the homozygote

${ }^{b}$ Percentage of phenotypic variance explained by the QTL

${ }^{c}$ LOD (logarithm of the odds) above the threshold at the 0.05 level of probability obtained through a 1000 -iteration permutation test based on overall means. For readability, only selected markers are shown. Loci closest to the QTL peak of FHB severity are in bold. QTL bars span an LOD drop of 1.5 from maximum LOD

conferred resistance. These QTL were found in single greenhouse experiments only and, contrary to the QTL at the Fhbl locus, were not considered as stable.

\section{QTL analysis for plant height and flowering date}

QTL for plant height were detected on 4AL, 4BS and 6AS to which DBC-480 alleles contributed to increased height (Table 5). The Rht-Bl locus on 4BS was significant in all populations and explained 95,81 and $37 \%$ of the variation for $\mathrm{PH}$ in the KD, DD and SD population. In the SD population, two further QTL were associated with $\mathrm{PH}$ on $4 \mathrm{AL}$ and $6 \mathrm{AS}$. The main effects were 11 and $27 \%$ for $4 \mathrm{AL}$ and 6AS, while epistatic interaction was evident for both loci with the Rht-B1 locus. The percentage of variation explained by the interaction of 4ALx4BS and 6ASx4BS 
Table 5 Locations and estimates of QTL for plant height $(\mathrm{cm})$ and flowering date (days after May 1st) using multiple QTL mapping

\begin{tabular}{|c|c|c|c|c|c|c|}
\hline Trait & Population & CHR & Closest marker & $\operatorname{Add}^{\mathrm{a}}$ & $\% \mathrm{PV}^{\mathrm{b}}$ & $\overline{\operatorname{LOD}^{c}}$ \\
\hline \multirow[t]{7}{*}{ Plant height } & $\mathrm{SD}$ & $4 \mathrm{AL}$ & 4541598 & -5.6 & 10.8 & 22.7 \\
\hline & $\mathrm{KD}$ & 4BS & RhtB1 & -17.4 & 95.4 & 74.4 \\
\hline & DD & 4BS & RhtB1 & -14.9 & 81.4 & 36.2 \\
\hline & SD & 4BS & RhtB1 & -11.0 & 37.0 & 45.8 \\
\hline & $\mathrm{SD}$ & $6 \mathrm{AS}$ & 4008755 & -9.0 & 27.2 & 38.6 \\
\hline & SD & 4BSx4AL & & 3.6 & 3.6 & 9.5 \\
\hline & SD & 4BSx6AS & & 4.5 & 7.3 & 16.3 \\
\hline \multirow[t]{8}{*}{ Flowering date } & DD & $1 \mathrm{BL}$ & 4009852 & -0.3 & 6.9 & 3.6 \\
\hline & $\mathrm{KD}$ & 2BS & 1238155 & 0.3 & 11.6 & 5.0 \\
\hline & DD & 2BS & 4404789 & 0.8 & 44.3 & 16.8 \\
\hline & SD & $2 \mathrm{BS}$ & 988615 & 0.4 & 10.8 & 3.9 \\
\hline & SD & $4 \mathrm{AL}$ & 4541598 & 0.5 & 16.6 & 5.7 \\
\hline & $\mathrm{KD}$ & $5 \mathrm{AL}$ & 1148774 & -0.6 & 37.8 & 13.6 \\
\hline & SD & $6 \mathrm{AS}$ & 4008755 & 0.5 & 20.4 & 6.8 \\
\hline & DD & $6 \mathrm{BS}$ & 1077913 & 0.3 & 7.1 & 3.7 \\
\hline
\end{tabular}

a Positive additive effects denote trait-increasing effect of the DBC-480 allele; additive effects were estimated as half the difference between phenotype averages for the homozygote

b Percentage of phenotypic variance explained by the QTL

${ }^{c}$ LOD (logarithm of the odds) above the threshold at the 0.05 level of probability obtained through a 1000 -iteration permutation test was low compared to the main effects of each locus contributing to 4 and $7 \%$ of the phenotypic variance. QTL detection for flowering date revealed significant QTL on 1BL, 2BS, 4AL, 5AL, 6AS and 6BS (Table 5). The DBC480 allele contributed to a delayed flowering of RILs carrying it on QTL 2BS, 4AL, 5AL, 6AS and 6BS. The QTL on 2BS was found at the same position in all three populations and mapped at a location distal from the QTL for FHB severity identified in the KD population on 2BL. This QTL had the strongest effect in the DD population where it explained $44 \%$ of the phenotypic variation. In the SD population, co-localization of QTL for FHB severity, PH and date of anthesis were found on 4AL and 6AS and thus these loci appeared to have pleiotropic effects.

\section{Association between FHB resistance QTL and plant height QTL}

The target genotype for a durum wheat breeder is a semidwarf plant type with improved FHB resistance. To investigate the feasibility of such an ideotype in our populations, we compared the effects of the detected FHB resistance QTL. In the SD population the three major resistance QTL mapping to Rht-B1, 4AL and 6AS overlapped with the QTL for PH. The effect of Fhbl-the only QTL not associated with PH in this population-does not efficiently counteract the increased susceptibility associated with the short-stemmed allele at the Rht-B1, 4AL and $6 \mathrm{AS}$ loci. In the KD and DD populations, only the Rht-BI loci contributed to both FHB severity and PH, while two other QTL, including Fhbl, were not associated with this morphological trait. To investigate the effects of allele combinations at the FHB resistance loci on FHB severity and PH, the RILs of each population were first classified in subgroups according to their allele status at the detected resistance QTL as illustrated in Fig. 3. The resistance level and average height were then compared among the different subgroups. In both populations, lines carrying the dwarfing allele $R h t-B 1 b$ were significantly shorter and more susceptible than the ones harboring the wild-type allele Rht-Bla. Plant height on average was reduced by 31 and $25 \%$ in the KD and DD Rht-Blb subpopulations, respectively, but the level of disease symptoms relative to Rht-Bla were about twofold increased. In the KD population, lines carrying both resistance QTL at $F h b 1$ and 2BL loci in combination with Rht-B1b had between 22 and $38 \%$ less disease severity than the dwarf lines carrying one or no resistance QTL while showing equivalent levels of resistance as lines carrying Rht-Bla with no supplementary resistance QTL. In the DD population, the FHB resistance levels of dwarf lines carrying positive alleles at $F h b 1$ and 5AL were not significantly different from any Rht-Bla subpopulation while being $53 \%$ less diseased than dwarf lines with no resistance QTL. Taken together, our findings demonstrate that the combination of $3 \mathrm{BS}+2 \mathrm{BL}$ QTL in the KD population and $3 \mathrm{BS}+5 \mathrm{AL}$ in the DD population efficiently offset the negative effect of $R h t-B 1 b$ on FHB resistance. 


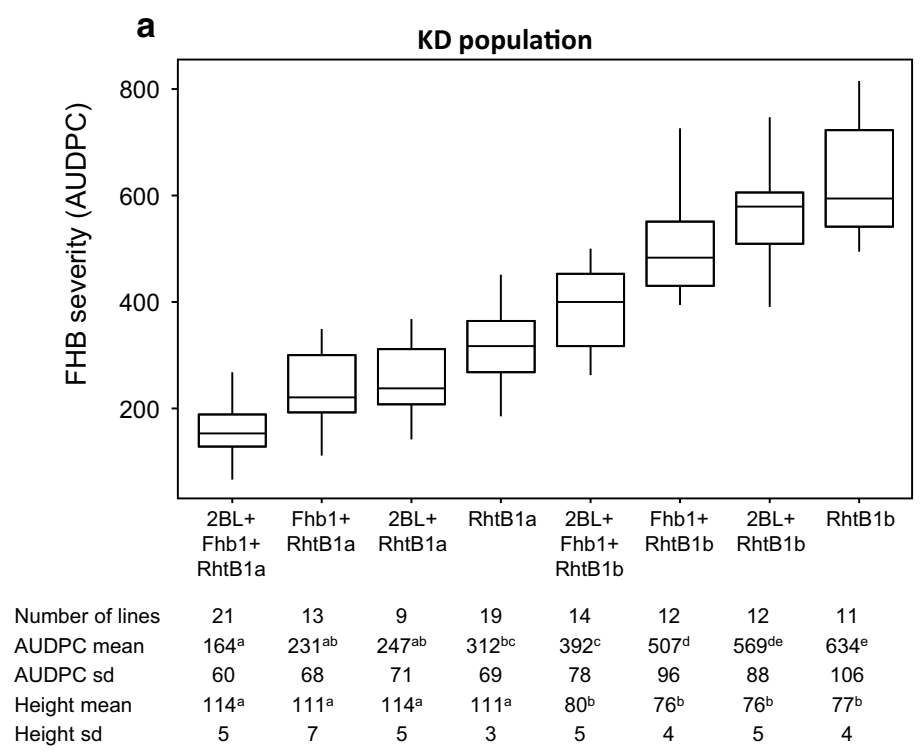

b DD population

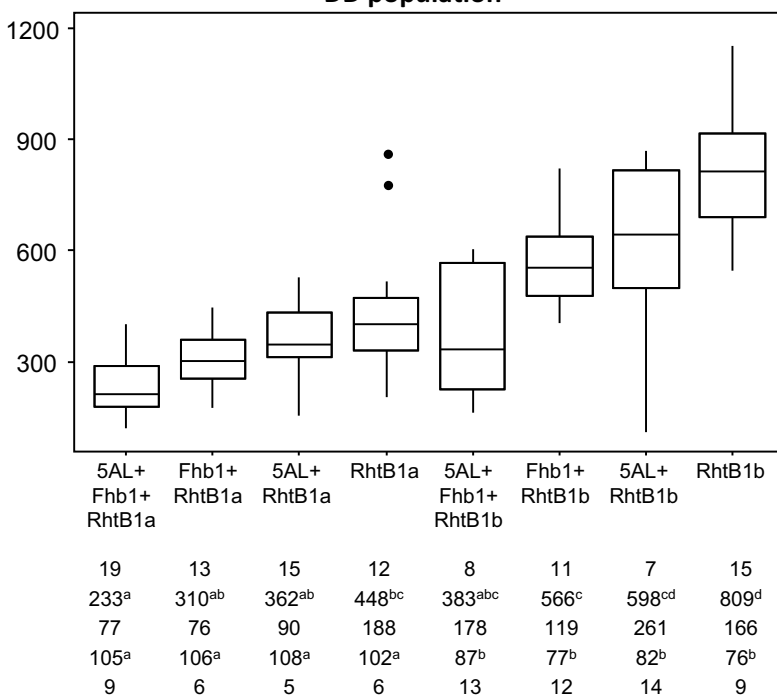

Fig. 3 Box plot distributions of RILs according to their allele combinations at the FHB resistance loci for the KD (a) and DD (b) populations for overall mean FHB severity (AUDPC). Medians are indicated by solid lines, points represent outliers. For each subgroup, the

\section{Discussion}

FHB resistance has become a priority in durum wheat breeding programs in the last decades. The limited sources of resistance available in durum wheat have urged breeders in incorporating FHB resistance from related species. In this research work, resistance derived from common wheat was investigated for the first time in the genetic background of durum wheat. The resistant line DBC-480, which carries the major common wheat resistance QTL Fhbl, presented enhanced resistance in field and greenhouse experiments after artificial inoculation. The use of three different F7-RIL populations allowed the dissection of the genetic basis of FHB resistance and to concomitantly validate the effects of the detected QTL in the different elite durum backgrounds.

Quantitative variation for FHB symptoms was evident in all three populations and for both inoculation techniques. FHB severity and FHB spread were significantly, but weakly correlated. This low correlation between the two FHB-related traits may be explained by the different mechanisms of infection accounted for by the two inoculation methods. FHB severity assessed after spray inoculation in the field accounts for both resistance to primary infection and subsequent spread of the symptoms within the heads. This measure evaluates thus a combination of type 1 and type 2 resistance under conditions that mimic natural epidemics, while single-floret inoculation estimates solely type 2 component of resistance. Reports have shown that type 1 number of lines, mean values and standard deviations of FHB severity (AUDPC) and plant height $(\mathrm{cm})$ are indicated. Values followed by different letters are significantly different $(p<0.05)$ based on Tukey test

and type 2 resistance vary independently among cultivars (Schroeder and Christensen 1963) and are likely controlled by different genes (Buerstmayr et al. 2003a). Additionally, a high negative correlation between plant height and FHB resistance was evident in the field trials, while no association between these traits was observed in the greenhouse experiments. The discrepancy of plant height influencing FHB response between the two inoculation methods may also contribute to this low correlation, as several reports have pointed out that type 2 resistance is less affected by plant height than type 1 resistance (Steiner et al. 2004; Srinivasachary et al. 2008, 2009; Lu et al. 2011).

\section{Genetic architecture of FHB resistance}

The genetic architecture of FHB resistance in our populations appears to be quantitative and oligo- to polygenic. A total of six QTL located on chromosome arms 2BL, 3BS, 4AL, 4BS, 5AL and 6AS were repeatedly associated with enhanced resistance and DBC-480 contributed the favorable alleles at all loci. Genotyping of the populations was performed using GBS DArTseq marker technology supplemented with DNA markers specific to Fhbl and Rht-Bl. Comparisons of QTL positions were performed based on the consensus wheat map provided by DArT PL (A. Kilian, Diversity Arrays Technologies, personal communication, 2016), which includes DArTseq GBS, DArT and SSR markers, and consensus maps published by Somers et al. (2004) and Marone et al. (2012). It appears that the 
genomic regions found to be responsible for FHB resistance in our study coincide with locations where QTL have already been identified in common wheat.

The QTL on 3BS mapped at the Fhbl locus near Xbarc147 and Xumn10 was found repeatedly in all populations. The effect of $F h b l$ on FHB severity varied and, depending on the durum genetic background and the individual experiments, explained between 5 and $16 \%$ of the phenotypic variance. In the different populations, the Fhbl resistance allele reduced FHB severity symptoms on average by $30 \%$ in the $\mathrm{KD}$ and $36 \%$ in the DD populations, while in the SD population the resistance was only increased by $6 \%$. The discrepancies observed among the $\mathrm{KD}$ and DD populations on one side, and the SD population on the other, may be due to differences in their respective resistance genetic architecture. In the $\mathrm{KD}$ and $\mathrm{DD}$ populations, only one further major QTL affecting FHB severity was detected and similar effects for $F h b l$ were observed, while in the SD population the relative effect of Fhb1 may be diminished by the presence of three further major QTL. When evaluating FHB spread after single-floret inoculation, the Fhbl locus had a large effect explaining $33 \%$ of the total phenotypic variance. Our study demonstrates that in durum wheat, $F h b l$ is effective in providing type 2 resistance in a similar way as established in common wheat where $F h b 1$ improves mainly type 2 resistance and to a lesser extent type 1 resistance (Waldron et al. 1999; Anderson et al. 2001; Buerstmayr et al. 2002, 2003a; Cuthbert et al. 2006). Fhbl is a well-characterized QTL descending from the Asian cultivar Sumai-3 which has been found in numerous QTL studies (Buerstmayr et al. 2009). In tetraploid wheat, a resistance QTL has also been found in proximity of the $F h b l$ genomic region in the durum cultivar Floradur (Buerstmayr et al. 2012) and in Tunisian durum landraces (Ghavami et al. 2011). However, haplotype comparison using SSR markers by Buerstmayr et al. (2012) revealed different alleles for Sumai-3 and Floradur at the $F h b 1$ locus, indicating thus the existence of different QTL alleles at this locus. We report here the first successful deployment of Fhbl in durum wheat which marks a significant step forward in durum wheat breeding toward improving FHB resistance. Common wheat represents a useful reservoir of resistance for durum wheat, as most of the QTL that have been identified are located on the A and B genomes (Buerstmayr et al. 2009; Liu et al. 2009; Löffler et al. 2009). The difficulties pointed out in previous studies when transferring resistance QTL from common wheat into durum wheat may be attributed to complex interactions of genes among the A, B and D genomes as emphasized in a recent study by Zhu et al. (2016a). In our study, no epistatic interactions that may modulate the effect of $F h b l$ were detected. The absence of the $\mathrm{D}$ genome in durum wheat, hypothesized to carry factors that enhance resistance
(Fakhfakh et al. 2011), has been speculated as one of the limiting factors for effective deployment of resistance from hexaploid wheat. Our results show that the presence of the D genome appears to be not required for efficient expression of Fhbl in durum wheat. Comparing the effect of $F h b 1$ in durum wheat with previous studies is not trivial, due to a wide range of phenotypic variances reported for this QTL in common wheat (Buerstmayr et al. 2009). In studies evaluating type 2 resistance in common wheat, $R^{2}$ values for Fhbl ranged between 11\% (Yang et al. 2005) and 60\% (Bai et al. 1999), while in spray-inoculated field trials Buerstmayr et al. (2003a) reported an $R^{2}$ of $29 \%$. The resistance-improving effect of Fhbl in our durum wheat populations is in a similar range as reported in a series of near isogenic lines in common wheat by Pumphrey et al. (2007), who found an average reduction of disease severity by $23 \%$, though varying from 0 to $70 \%$. Differences in population size, genetic background, inoculation techniques and environments in which the evaluations were performed can all be reasons for these variations. While in the literature, there are speculations that durum wheat may carry or lack certain genetic factors that modulate the resistance-improving effect of $F h b 1$ (Rudd et al. 2001), we find no evidence to support this hypothesis.

A major QTL on 4BS associated with FHB severity was found in all three populations with effects of different magnitude. The location of the QTL coincided with the Rht-BI gene. The QTL was responsible for the greatest amount of variation for resistance in the KD and DD populations, while in the SD population the QTL had a major effect but was not the greatest contributor to FHB resistance. As mentioned previously, the discrepancy of effects observed is certainly due to differences in genetic backgrounds. In all cases, the reduced height allele $R h t-B 1 b$ accounted for higher disease severity. Such associations of the semidwarf $R h t-B 1 b$ allele with increased FHB severity have been previously reported in hexaploid wheat (Hilton et al. 1999; Srinivasachary et al. 2009). Supporting results have also been found in three durum wheat backcross populations from crosses of the tall and FHB-resistant donor $T$. dicoccum-line 161 to the semi-dwarf durum wheat lines Helidur, Floradur and DS-131621. The resistance QTL at the Rht-B1 locus was the most important QTL affecting FHB resistance after spray inoculation and in all three populations, plants carrying the Rht-Blb allele showed higher FHB severity scores (Buerstmayr et al. 2012).

In the SD population, two further major QTL were detected on 4AL and 6AS. Both resistance QTL overlapped with QTL for flowering date and plant height. QTL have been already identified on $4 \mathrm{~A}$ and $6 \mathrm{~A}$ in tetraploid wheat; however, they appear to be located on different chromosome arms and do not match the position of the QTL identified in our study. Gladysz et al. (2007) identified a QTL for 
type 2 resistance derived from the resistant $T$. dicoccoides accession Mt.Hermon\#22 near Xgwm610 which mapped on the short arm of chromosome 4A, while Buerstmayr et al. (2012) found a small effect QTL for FHB severity derived from T.dicoccum-line 161 in a cross with line DS-131621 near Xgwm356 on 6AL. Meanwhile, several mapping projects performed in hexaploid wheat identified QTL in the same region of $4 \mathrm{AL}$ in the US winter wheat Heyne (Zhang et al. 2012) and in the Swiss winter wheat Arina (Paillard et al. 2004; Buerstmayr and Buerstmayr 2015). No coinciding QTL for flowering date or plant height were reported, but an overlap with QTL for anther retention was found in the Arina/Capo population (Buerstmayr and Buerstmayr, 2015). The QTL on 6AS mapped to a similar position as the type 2 resistance QTL identified in hexaploid wheat in the ND2603/Butte86 population derived from the resistant line ND2603 (Sumai 3/Wheaton) (Anderson et al. 2001).

In the KD population, a minor effect QTL was found on $2 \mathrm{BL}$ at the proximity of the centromere. This region has been reported to carry resistance QTL in two unrelated tetraploid wheat populations where the susceptible durum wheat parents Strong field (Somers et al. 2006) and Helidur (Gladysz et al. 2007) contributed to the resistance-improving allele. These QTL were detected after point inoculation providing type 2 resistance, while the QTL identified in our study was found after spray inoculation.

Another QTL for FHB severity was identified on 5AL in the DD population, which had a major effect in 2013 but remained undetected in 2014 and 2015. In the DD population, very few GBS markers were polymorphic on chromosome 5A making exact positioning of the QTL difficult. To improve map density, 21 SSR markers were additionally screened, yet none was found to be polymorphic suggesting close genetic relatedness of the parental lines for this genomic region. Comparison with previous studies is therefore difficult, but map comparison suggests that the QTL does not map to the same region as the major hexaploid wheat QTL on 5A Qfhs.ifa-5A derived from Sumai-3 which is located close to the centromere (Buerstmayr et al. 2003a).

\section{Association of QTL for FHB resistance, flowering date and plant height}

In our study six QTL were found associated with flowering date. Co-localization of QTL for flowering date and FHB resistance was evident for the SD population on $4 \mathrm{AL}$ and 6AS. The two QTL exert a strong effect on both traits for which a positive correlation was observed. In the KD and DD populations, weak and non-significant correlations were found, and when individual experiments were analyzed separately, the correlations varied greatly. No general pattern was evident for the association between earliness and the level of FHB symptoms in these two populations. This non-dependency may be attributed to the absence of overlapping QTL for these two traits, while environmentspecific factors around flowering and inoculation may account for variability in the correlations observed in individual experiments.

In contrast, plant height was significantly negatively correlated with FHB severity in all three populations, which is in agreement with previous findings (Talas et al. 2011; Buerstmayr et al. 2012; Miedaner and Longin 2014). All PH QTL identified in this study coincided with QTL for FHB severity on chromosomes 4AL, 4BS and 6AS. Colocalization of PH and FHB severity QTL is a common feature in wheat and supported by meta-QTL analysis (Mao et al. 2010). The mechanisms of association between the two traits are complex and may be attributed to the effects of height differences per se and/or to pleiotropic effects of the dwarfing genes or tightly linked genes that increase FHB susceptibility. The mutant allele $R h t-B l b$, as well as its homoeologous allele $R h t-D 1 b$ on chromosome $4 \mathrm{D}$, encodes single nucleotide polymorphism (SNP) mutations in the DELLA domain that create a premature stop codon that is responsible for reduced sensitivity to the phytohormone gibberellin leading to shorter plant height (Peng et al. 1999; Hedden and Sponsel 2015). DELLA proteins have been shown to be associated with abiotic and biotic stress tolerance (Achard and Genschik 2009) and, in the case of FHB, a DELLA protein mutation may have physiological effects linked to changes in cell death response (Saville et al. 2012). Alternatively to these genetic effects, differences in microclimatic conditions around the heads of tall and dwarf genotypes have been considered to play a significant role particularly under field conditions, with short plants being exposed to higher infection pressure than tall plants (Yan et al. 2011). The Rht-Blb allele is also known to have pleiotropic effects on different morphological and structural traits including reduced peduncle length and increased cell density, which may also affect response to FHB. In common wheat, Rht-Blb and Rht-Dlb were found to be associated with reduced anther extrusion, which was supposed to partly explain their association with higher FHB susceptibility (Buerstmayr and Buerstmayr 2016). In the case of our study, all features may be important. The strong effect of the QTL on 4BS, coinciding with the reduced height gene Rht-B1, on PH and FHB severity was evident in all populations. The Rht-B1 locus explained 95, 81 and $37 \%$ of the variation for $\mathrm{PH}$ and 64,38 and $19 \%$ of the variation for FHB severity in the KD, DD and SD populations, respectively. In the SD population, the two additional QTL on 4AL and 6AS exerted at the same time strong effect on plant height and FHB resistance. The QTL on 4AL mapped to a similar region as a QTL associated with $\mathrm{PH}$ in hexaploid wheat corresponding to a kaurenoic 
acid oxidase (KAO) gene (Khlestkina et al. 2010; Zanke et al. 2014), while reduced height genes have been reported on 6AS in durum wheat (Haque et al. 2011). These genes are gibberellin-sensitive and not comparable to Rht-Bl in that aspect. In agreement with Yan et al. (2011), we hypothesize that considering the large variation for plant height with differences of about $60 \mathrm{~cm}$ between the shortest and the tallest plants, part of the apparent negative correlation, may be attributed to plant height per se. Even under spray inoculation and mist irrigation, heads of short plants tend to remain more humid and therefore under more severe infection pressure than heads of tall plants. This is in agreement with Buerstmayr et al. (2012), who evaluated FHB severity of three durum wheat populations with similarly large variation for plant height as observed in our present study and argued for a probable disease escape of tall lines despite controlled mist irrigation after spray inoculation.

\section{Perspective for durum wheat breeding and conclusion}

Obviously, in our populations, plant height had a strong influence on modulating FHB disease response. The increased FHB susceptibility associated with medium to short height plant and with $R h t-B l b$ is challenging for durum wheat breeders. Rht-Blb confers beneficial attributes linked to higher yield and harvest index concomitant to the desired reduced plant height, thereby limiting lodging, in plant production systems with modern agronomic practices (Royo et al. 2007; Subira et al. 2016). We show that the successful deployment of Fhbl in combination with minor effect QTL enabled the discovery and the selection of semi-dwarf lines with upsurge levels of resistance. These results are in agreement with a previous report in hexaploid wheat where pyramiding two resistance QTL balanced the negative effect of the semi-dwarf allele $R h t-D l b$ to achieve improved levels of resistance in semi-dwarf wheat $(\mathrm{Lu}$ et al. 2011). The progeny lines of the KD and DD populations carrying favorable allele combinations at the Rht-BI and Fhbl loci, and additional FHB resistance alleles on $2 \mathrm{BL}$ or $5 \mathrm{AL}$ provide unique and novel resources for durum wheat breeding. The introgression of Fhbl by recurrent backcrossing into durum wheat to develop the resistant experimental line DBC- 480 and its crossing to elite durum cultivars enabled the development of novel FHB-resistant breeding lines that are agronomically close to modern European germplasm. These novel improved lines are thus readily incorporable into practical durum wheat breeding programs for enhancing FHB resistance.

Author contribution statement NP performed the study and drafted the manuscript. CG, UP and EW helped to collect phenotypic data and genotyping of markers. BS carried out the initial crosses and developed the plant material used in this study. TL, OR and HB initiated the study and obtained funding. The manuscript was finally approved by all coauthors.

Acknowledgements We appreciate Marc Lemmens and Imer Maloku for providing the Fusarium inoculum. We are grateful to Andrzej Kilian from DArT PL for giving us access to the DArTseq consensus map. We thank Wolfgang Schweiger and Sebastian Michel for critically reviewing this manuscript. We acknowledge financial support from the French Ministry of Higher Education and Research, Conventions Industrielles de Formation par la REcherche (CIFRE) funding 2012/1405. Open access funding provided by University of Natural Resources and Life Sciences Vienna (BOKU).

\section{Compliance with ethical standards}

Conflict of interest The authors declare that they have no conflict of interest.

Open Access This article is distributed under the terms of the Creative Commons Attribution 4.0 International License (http://creativecommons.org/licenses/by/4.0/), which permits unrestricted use, distribution, and reproduction in any medium, provided you give appropriate credit to the original author(s) and the source, provide a link to the Creative Commons license, and indicate if changes were made.

\section{References}

Achard P, Genschik P (2009) Releasing the brakes of plant growth: How GAs shutdown DELLA proteins. J Exp Bot 60:1085-1092

Anderson JA, Stack RW, Liu S, Waldron BL, Fjeld AD, Coyne C, Moreno-Sevilla B, Fetch JM, Song QJ, Cregan PB, Frohberg RC (2001) DNA markers for Fusarium head blight resistance QTLs in two wheat populations. Theor Appl Genet 102:1164-1168

Anderson JA, Chao SM, Liu SX (2007) Molecular breeding using a major QTL for Fusarium head blight resistance in wheat. Crop Sci 47:S112-S119

Bai G, Kolb FL, Shaner G, Domier LL (1999) Amplified fragment length polymorphism markers linked to a major quantitative trait locus controlling scab resistance in wheat. Phytopathology 89:343-348

Bates D, Mächler M, Bolker B, Walker S (2015) Fitting linear mixedeffects models using lme4. J Stat Softw Oct 67:1-48

Broman KW, Wu H, Sen S, Churchill GA (2003) R/qt1: QTL mapping in experimental crosses. Bioinformatics 19:889-890

Buerstmayr M, Buerstmayr H (2015) Comparative mapping of quantitative trait loci for Fusarium head blight resistance and anther retention in the winter wheat population Capo $\times$ Arina. Theor Appl Genet 128:1519-1530

Buerstmayr M, Buerstmayr H (2016) The semi-dwarfing alleles $R h t-D 1 b$ and Rht-Blb show marked differences in their associations with anther-retention in wheat heads and with Fusarium head blight susceptibility. Phytopathology. doi:10.1094/ PHYTO-05-16-0200-R

Buerstmayr H, Steiner B, Lemmens M, Ruckenbauer P (2000) Resistance to Fusarium head blight in winter wheat: heritability and trait associations. Crop Sci 40:1012-1018

Buerstmayr H, Lemmens M, Hartl L, Doldi L, Steiner B, Stierschneider M, Ruckenbauer P (2002) Molecular mapping of QTLs for 
Fusarium head blight resistance in spring wheat. I. Resistance to fungal spread (type II resistance). Theor Appl Genet 104:84-91

Buerstmayr H, Steiner B, Hartl L, Griesser M, Angerer N, Lengauer D, Miedaner T, Schneider B, Lemmens M (2003a) Molecular mapping of QTLs for Fusarium head blight resistance in spring wheat. II. Resistance to fungal penetration and spread. Theor Appl Genet 107:503-508

Buerstmayr H, Stierschneider M, Steiner B, Lemmens M, Grisser M, Nevo E, Fahima T (2003b) Variation for resistance to head blight caused by Fusarium graminearum in wild emmer (Triticum dicoccoides) originating from Israel. Euphytica 130:17-23

Buerstmayr H, Ban T, Anderson J (2009) QTL mapping and marker assisted selection for Fusarium head blight resistance in wheat: a review. Plant Breed 128:1-26

Buerstmayr M, Huber K, Heckmann J, Steiner B, Nelson J, Buerstmayr H (2012) Mapping of QTL for Fusarium head blight resistance and morphological and developmental traits in three backcross populations derived from Triticum dicoccum $\times$ Triticum durum. Theor Appl Genet 125:1751-1765

Buerstmayr M, Alimari A, Steiner B, Buerstmayr H (2013) Genetic mapping of QTL for resistance to Fusarium head blight spread (type 2 resistance) in a Triticum dicoccoides $\times$ Triticum durum backcross-derived population. Theor Appl Genet 126:2825-2834

Chen X, Faris J, Hu J, Stack R, Adhikari T, Elias E, Kianian S, Cai X (2007) Saturation and comparative mapping of a major Fusarium head blight resistance QTL in tetraploid wheat. Mol Breed 19:113-124

Covarelli L, Beccari G, Prodi A, Generotti S, Etruschi F, Juan C, Ferrer E, Mañes J (2014) Fusarium species, chemotype characterisation and trichothecene contamination of durum and soft wheat in an area of central Italy. J Sci Food Agric 95:540-551

Cuthbert PA, Somers DJ, Thomas J, Cloutier S, Brulé-Babel A (2006) Fine mapping Fhb1, a major gene controlling fusarium head blight resistance in bread wheat (Triticum aestivum L.). Theor Appl Genet 112:1465-1472

Elias E, Manthey F, Stack R, Kianian S (2005) Breeding efforts to develop Fusarium head blight resistant durum wheat in North Dakota. In: Canty S, Lewis J, Siler L, Ward R (eds) Proceedings of the National Fusarium Head Blight Forum. East Lansing: Michigan State University, Milwaukee, pp 25-26

Ellis MH, Spielmeyer W, Gale KR, Rebetzke GJ, Richards RA (2002) "Perfect" markers for the Rht-B1b and Rht-D1b dwarfing genes in wheat. Theor Appl Genet 105:1038-1042

Fakhfakh M, Yahyaoui A, Rezgui S, Elias E, Daaloul A (2011) Inheritances of Fusarium head blight resistance in a cross involving local and exotic durum wheat cultivars. Crop Sci 51:2517-2524

Ghavami F, Elias E, Mamidi S, Ansari O, Sargolzaei M, Adhikari T, Mergoum M, Kianian S (2011) Mixed model association mapping for Fusarium head blight resistance in Tunisian-derived durum wheat populations. G3 1:209-218

Gilbert J, Haber S (2013) Overview of some recent research developments in fusarium head blight of wheat. Can J Plant Pathol 35:149-174

Gladysz C, Lemmens M, Steiner B, Buerstmayr H (2007) Evaluation and genetic mapping of resistance to Fusarium head blight in Triticum dicoccoides. Isr J Plant Sci 55:263-266

Haque M, Martinek P, Watanabe N, Kuboyama T (2011) Genetic mapping of gibberellic acid-sensitive genes for semi-dwarfism in durum wheat. Cereal Res Commun 39:171-178

Hedden P, Sponsel V (2015) A century of gibberellin research. J Plant Growth Regul 34:740-760

Hilton AJ, Jenkinson P, Hollins TW, Parry DW (1999) Relationship between cultivar height and severity of Fusarium ear blight in wheat. Plant Pathol 48:202-208
Holland JB, Nyquist WE, Cervantes-Martinez CT (2003) Estimating and interpreting heritability for plant breeding: an update. Plant Breed Rev 22:9-112

Huhn M, Elias E, Ghavami F, Kianian S, Chao S, Zhong S, Alamri M, Yahyaoui A, Mergoum M (2012) Tetraploid Tunisian wheat germplasm as a new source of Fusarium head blight resistance. Crop Sci 52:136-145

Khlestkina EK, Kumar U, Roeder MS (2010) Ent-kaurenoic acid oxidase genes in wheat. Mol Breed 25:251-258

Kumar S, Stack R, Friesen T, Faris J (2007) Identification of a novel Fusarium head blight resistance quantitative trait locus on chromosome 7A in tetraploid wheat. Phytopathology 97:592-597

Li H, Vikram P, Singh RP, Kilian A, Carling J, Song J, Burgueno-Ferreira JA, Bhavani S, Huerta-Espino J, Payne T, Sehgal D, Wenzl P, Singh S (2015) A high density GBS map of bread wheat and its application for dissecting complex disease resistance traits. BMC Genom 16:216-231

Liu SX, Pumphrey MO, Gill BS, Trick HN, Zhang JX, Dolezel J, Chalhoub B, Anderson JA (2008) Toward positional cloning of $F h b 1$, a major QTL for Fusarium head blight resistance in wheat. Cereal Res Commun 36:195-201

Liu S, Hall MD, Griffey CA, McKendry AL (2009) Meta-Analysis of QTL associated with fusarium head blight resistance in wheat. Crop Sci 49:1955-1968

Löffler M, Schön CC, Miedaner T (2009) Revealing the genetic architecture of FHB resistance in hexaploid wheat (Triticum aestivum L.) by QTL meta-analysis. Mol Breed 23:473-488

Lu Q, Szabo-Hever A, Bjornstad A, Lillemo M, Semagn K, Mesterhazy A, Ji F, Shi J, Skinnes H (2011) Two major resistance quantitative trait loci are required to counteract the increased susceptibility to Fusarium head blight of the Rht-D1B dwarfing gene in wheat. Crop Sci 51:2430-2438

Mao S, Wei Y, Cao W, Lan X, Yu M (2010) Confirmation of the relationship between plant height and Fusarium head blight resistance in wheat (Triticum aestivum L.) by QTL meta-analysis. Euphytica 174:343-356

Marone D, Laidò G, Gadaleta A, Colasuonno P, Ficco D, Giancaspro A, Giove S, Panio G, Russo M, De Vita P, Cattivelli L, Papa R, Blanco A, Mastrangelo A (2012) A high-density consensus map of A and B wheat genomes. Theor Appl Genet 125:1619-1638

McMullen M, Bergstrom G, De Wolf E, Dill-macky R, Hershman D, Shaner G, Van Sanford D (2012) A unified effort to fight an enemy of wheat and barley: Fusarium head blight. Plant Dis 96:1712-1728

Mesterházy A (1995) Types and components of resistance to Fusarium head blight of wheat. Plant Breed 114:377-386

Miedaner T, Longin CFH (2014) Genetic variation for resistance to Fusarium head blight in winter durum material. Crop Pasture Sci 65:46-51

Miedaner T, Voss H (2008) Effect of dwarfing genes on fusarium head blight resistance in two sets of near-isogenic lines of wheat and check cultivars. Crop Sci 48:2115-2122

Oliver R, Stack R, Miller J, Cai X (2007) Reaction of wild emmer wheat accessions to Fusarium head blight. Crop Sci 47:893-899

Oliver R, Cai X, Friesen T, Halley S, Stack R, Xu S (2008) Evaluation of Fusarium head blight resistance in tetraploid wheat (Triticum turgidum L.). Crop Sci 48:213-222

Otto C, Kianian S, Elias E, Stack R, Joppa L (2002) Genetic dissection of a major Fusarium head blight QTL in tetraploid wheat. Plant Mol Biol 48:625-632

Paillard S, Schnurbusch T, Tiwari R, Messmer M, Winzeler M, Keller B, Schachermayr G (2004) QTL analysis of resistance to Fusarium head blight in Swiss winter wheat (Triticum aestivum L.). Theor Appl Genet 109:323-332 
Parry DW, Jenkinson P, McLeod L (1995) Fusarium ear blight (scab) in small grain cereals-a review. Plant Pathol 44:207-238

Peng J, Richards DE, Hartley NM, Murphy GP, Devos KM, Flintham JE, Beales J, Fish LJ, Worland AJ, Pelica F, Sudhakar D, Christou P, Snape JW, Gale MD, Harberd NP (1999) "Green revolution" genes encode mutant gibberellin response modulators. Nature 400:256-261

Pestka JJ (2010) Deoxynivalenol: mechanisms of action, human exposure, and toxicological relevance. Arch Toxicol 84:663-679

Prat N, Buerstmayr M, Steiner B, Robert O, Buerstmayr H (2014) Current knowledge on resistance to Fusarium head blight in tetraploid wheat. Mol Breed 34:1689-1699

Pumphrey MO, Bernardo R, Anderson JA (2007) Validating the Fhbl QTL for fusarium head blight resistance in near-isogenic wheat lines developed from breeding populations. Crop Sci 47:200-206

R Core Team (2015) R: A language and environment for statistical computing. http://www.R-project.org/. Accessed 27 June 2016

Royo C, Álvaro F, Martos V, Ramdani A, Isidro J, Villegas D, García Del Moral LF (2007) Genetic changes in durum wheat yield components and associated traits in Italian and Spanish varieties during the 20th century. Euphytica 155:259-270

Ruan Y, Comeau A, Langevin F, Hucl P, Clarke J, Brule-Babel A, Pozniak C (2012) Identification of novel QTL for resistance to Fusarium head blight in a tetraploid wheat population. Genome $55: 853-864$

Rudd JC, Horsley RD, Mckendry AL, Elias EM (2001) Host plant resistance genes for Fusarium head blight: sources, mechanisms, and utility in conventional breeding systems. Crop Sci 41:620-627

Saghai-Maroof MA, Soliman KM, Jorgensen RA, Allard RW (1984) Ribosomal DNA spacer-length polymorphisms in barley: Mendelian inheritance, chromosomal location, and population dynamics. Proc Natl Acad Sci USA 81:8014-8018

Salameh A, Buerstmayr M, Steiner B, Neumayer A, Lemmens M, Buerstmayr H (2011) Effects of introgression of two QTL for fusarium head blight resistance from Asian spring wheat by marker-assisted backcrossing into European winter wheat on fusarium head blight resistance, yield and quality traits. Mol Breed 28:485-494

Saville RJ, Gosman N, Burt CJ, Makepeace J, Steed A, Corbitt M, Chandler E, Brown JKM, Boulton MI, Nicholson P (2012) The "Green Revolution" dwarfing genes play a role in disease resistance in Triticum aestivum and Hordeum vulgare. J Exp Bot 63:1271-1283

Schroeder HW, Christensen JJ (1963) Factors affecting resistance of wheat to scab caused by Gibberella zeae. Phytopathology $53: 831-838$

Schweiger W, Steiner B, Vautrin S, Nussbaumer T, Siegwart G, Zamini M, Jungreithmeier F, Gratl V, Lemmens M, Mayer KFX, Bérgès H, Adam G, Buerstmayr H (2016) Suppressed recombination and unique candidate genes in the divergent haplotype encoding Fhbl, a major Fusarium head blight resistance locus in wheat. Theor Appl Genet 129:1607-1623

Somers DJ, Isaac P, Edwards K (2004) A high-density microsatellite consensus map for bread wheat (Triticum aestivum L.). Theor Appl Genet 109:1105-1114

Somers D, Fedak G, Clarke J, Cao W (2006) Mapping of FHB resistance QTLs in tetraploid wheat. Genome 49:1586-1593

Song QJ, Shi JR, Singh S, Fickus EW, Costa JM, Lewis J, Gill BS, Ward R, Cregan PB (2005) Development and mapping of microsatellite (SSR) markers in wheat. Theor Appl Genet 110:550-560

Srinivasachary Gosman N, Steed A, Simmonds J, Leverington-Waite M, Wang Y, Snape J, Nicholson P (2008) Susceptibility to Fusarium head blight is associated with the Rht-D1b semi-dwarfing allele in wheat. Theor Appl Genet 116:1145-1153
Srinivasachary Gosman N, Steed A, Hollins T, Bayles R, Jennings P, Nicholson P (2009) Semi-dwarfing Rht-B1 and Rht-D1 loci of wheat differ significantly in their influence on resistance to Fusarium head blight. Theor Appl Genet 118:695-702

Steiner B, Lemmens M, Griesser M, Scholz U, Schondelmaier J, Buerstmayr H (2004) Molecular mapping of resistance to Fusarium head blight in the spring wheat cultivar Frontana. Theor Appl Genet 109:215-224

Subira J, Ammar K, Álvaro F, García del Moral LF, Dreisigacker S, Royo C (2016) Changes in durum wheat root and aerial biomass caused by the introduction of the Rht-B1b dwarfing allele and their effects on yield formation. Plant Soil 403:291-304

Talas F, Longin F, Miedaner T (2011) Sources of resistance to Fusarium head blight within Syrian durum wheat landraces. Plant Breed 130:398-400

Taylor J, Butler D (2015) ASMap: linkage map construction using the MSTmap algorithm. R package version 0.4-5. http://CRAN.Rproject.org/package $=$ ASMap. Accessed 27 June 2016

Voorrips RE (2002) MapChart: software for the graphical presentation of linkage maps and QTLs. J Hered 93:77-78

Voss H, Holzapfel J, Hartl L, Korzun V, Rabenstein F, Ebmeyer E, Coester H, Kempf H, Miedaner T (2008) Effect of the Rht-Dl dwarfing locus on Fusarium head blight rating in three segregating populations of winter wheat. Plant Breed 127:333-339

Waldron B, Moreno-Sevilla B, Anderson JA, Stack RW, Frohberg RC (1999) RFLP mapping of QTL for Fusarium head blight resistance in wheat. Crop Sci 39:805-811

Wilde F, Korzun V, Ebmeyer E, Geiger HH, Miedaner T (2007) Comparison of phenotypic and marker-based selection for Fusarium head blight resistance and DON content in spring wheat. Mol Breed 19:357-370

Wu Y, Bhat PR, Close TJ, Lonardi S (2008) Efficient and accurate construction of genetic linkage maps from the minimum spanning tree of a graph. PLoS Genet. doi:10.1371/journal. pgen. 1000212

Yan W, Li H, Cai S, Ma H, Rebetzke G, Liu C (2011) Effects of plant height on type I and type II resistance to fusarium head blight in wheat. Plant Pathol 60:506-512

Yang ZP, Gilbert J, Fedak G, Somers DJ (2005) Genetic characterization of QTL associated with resistance to Fusarium head blight in a doubled-haploid spring wheat population. Genome 48:187-196

Zanke CD, Ling J, Plieske J, Kollers S, Ebmeyer E, Korzun V, Argillier O, Stiewe G, Hinze M, Neumann K, Ganal MW, Röder MS (2014) Whole genome association mapping of plant height in winter wheat (Triticum aestivum L). PLoS One. doi:10.1371/ journal.pone. 0113287

Zhang X, Bai G, Bockus W, Ji X, Pan H (2012) Quantitative trait loci for Fusarium head blight resistance in US hard winter wheat cultivar Heyne. Crop Sci 52:1187-1194

Zhang Q, Axtman JE, Faris JD, Chao S, Zhang Z, Friesen TL, Zhong S, Cai X, Elias EM, Xu SS (2014) Identification and molecular mapping of quantitative trait loci for Fusarium head blight resistance in emmer and durum wheat using a single nucleotide polymorphism-based linkage map. Mol Breed 34:1677-1687

Zhu X, Zhong S, Cai X (2016a) Effects of D-genome chromosomes and their A/B-genome homoeologs on Fusarium head blight resistance in durum wheat. Crop Sci 56:1-10

Zhu X, Zhong S, Chao S, Gu YQ, Kianian SF, Elias E, Cai X (2016b) Toward a better understanding of the genomic region harboring Fusarium head blight resistance QTL Qfhs.ndsu-3AS in durum wheat. Theor Appl Genet 129:31-43 